\title{
Multisystemic Therapy Effects on Attempted Suicide by Youths Presenting Psychiatric Emergencies
}

\author{
STANLEY J. HUEY, Jr., Ph.D., SCOTT W. HENGGELER, Ph.D., MELISA D. ROWLAND, M.D., \\ COLLEEN A. HALLIDAY-BOYKINS, Ph.D., PHILLIPPE B. CUNNINGHAM, PH.D., SUSAN G. PICKREL, M.D., \\ AND JAMES EDWARDS, M.D.
}

\begin{abstract}
Objective: To evaluate the efficacy of multisystemic therapy (MST) in reducing attempted suicide among predominantly African American youths referred for emergency psychiatric hospitalization. Method: Youths presenting psychiatric emergencies were randomly assigned to MST or hospitalization. Indices of attempted suicide, suicidal ideation, depressive affect, and parental control were assessed before treatment, at 4 months after recruitment, and at the 1-year posttreatment follow-up. Results: Based on youth report, MST was significantly more effective than emergency hospitalization at decreasing rates of attempted suicide at 1-year follow-up; also, the rate of symptom reduction over time was greater for youths receiving MST. Also, treatment differences in patterns of change in attempted suicide (caregiver report) varied as a function of ethnicity, gender, and age. Moreover, treatment effects were found for caregiver-rated parental control but not for youth depressive affect, hopelessness, or suicidal ideation. Conclusions: Results generally support MST's effectiveness at reducing attempted suicide in psychiatrically disturbed youngsters, whereas the effects of hospitalization varied based on informant and youth demographic characteristics. J. Am. Acad. Child Adolesc. Psychiatry, 2004;43(2):183-190. Key Words: attempted suicide, multisystemic therapy, hospitalization, treatment moderators.
\end{abstract}

Attempted suicide is a significant mental health problem that affects nearly $9 \%$ of adolescents in the United States each year (Grunbaum et al., 2002). Although the vast majority of youth suicide attempts are nonlethal (King, 1997), attention to self-harm behavior is important for at least two primary reasons. First, suicidal individuals place enormous demands on the mental

Accepted September 29, 2003.

Dr. Huey is with the Department of Psychology and Program in American Studies and Ethnicity, University of Southern California; Drs. Henggeler, Rowland, Halliday-Boykins, Cunningham, and Edwards are with the Family Services Research Center, Department of Psychiatry and Behavioral Sciences, Medical University of South Carolina; and Dr. Pickrel is with Mercy Medical Center, Behavioral Health Unit, Roseburg, OR.

The research reported in this article was supported by NIMH grants R01MH51852 and R01MH51852, and AHRQ grant PO1 HS1087. Special thanks go to Sonja Schoenwald for her comments on an earlier draft of this manuscript.

Correspondence to Dr. Huey, Department of Psychology, University of Southern California, SGM 501, 3620 S. McClintock Avenue, Los Angeles, CA 90089-1061; e-mail: hueyj@usc.edu.

0890-8567/04/4302-0183@2004 by the American Academy of Child and Adolescent Psychiatry.

DOI: 10.1097/01.chi.0000101700.15837.f3 health system in terms of staff resources and financial costs, particularly within inpatient hospital settings (Centers for Disease Control and Prevention, 2002). Second, an episode of attempted suicide poses a significant risk for persistent psychosocial problems (e.g., criminal behavior, drug/alcohol problems, divorce) and future suicide completion (Brent et al., 1993b). Thus, interventions that reduce the frequency of attempted suicide could produce collateral benefits in terms of decreased suicide morbidity, increased quality of life, and mental health cost savings.

Although significant advances have been made in understanding the precursors to youth suicidality (Wagner, 1997), little is known about effective means for treating attempted suicide in youths. Whereas cognitive-behavioral and family-focused interventions show efficacy in ameliorating depressive symptoms (Rotheram-Borus et al., 2001), decreasing suicidal ideation (Rotheram-Borus et al., 1996, 2001), and increasing treatment satisfaction (Harrington et al., 1998) among suicidal adolescents, these approaches have not been more effective than control conditions in reducing the frequency of attempted suicide. 
There are several possible reasons why these treatment approaches have been of limited effectiveness. First, whereas a host of interpersonal (e.g., family conflict, life stress) and intrapersonal (e.g., hopelessness, depression, poor problem-solving ability) factors are implicated as precursors to suicidal behavior (e.g., Lewinsohn et al., 1996), many extant interventions for suicidal youths focus on cognitive factors (Shaffer and Piacentini, 1994), and while involving other family members (e.g., Piacentini et al., 1995), they usually fail to address the larger set of factors in the youth's social ecology suggested as contributors to suicidal behavior (e.g., school problems, interpersonal conflict, caregiver mental health problems). Second, many interventions are conducted in hospitals or mental health settings rather than in the natural ecology (i.e., home or community), thus creating substantial barriers to service access that may contribute to high rates of noncompliance and treatment nonattendance among suicidal youths (Spirito et al., 1992; Swedo, 1989). Finally, standard interventions for suicidal youths are typically brief by design (e.g., most involve 10 or fewer contact hours) and may be of insufficient intensity and duration to affect the long-term trajectory of attempted suicide (Brent et al., 1993a). Thus, there appears to be a considerable gap between the complex needs of suicidal youths and the comprehensiveness of existing services for treating these youths.

In light of this gap, the present study was designed to determine whether an intensive family- and community-based treatment (multisystemic therapy [MST]) (Henggeler et al., 2002) could serve as a safe and effective alternative to the inpatient hospitalization of youths presenting psychiatric emergencies. MST is an evidence-based treatment that has a strong track record in treating the complex needs of serious juvenile offenders (e.g., U.S. Public Health Service, 2001) and shows promise in the treatment of serious emotional disturbance (e.g., Kazdin and Weisz, 1998). Such promise is evidenced by the high family engagement and treatment completion rates demonstrated in MST programs (Henggeler et al., 1998); the ability of MST to modify risk factors (e.g., substance use, family difficulties, behavior problems, caregiver and youth psychiatric distress) across the youth and family's social ecology (Henggeler et al., 2002); and the capacity of MST to deliver intensive services (lasting 3-5 months) due to the use of a home-based model of service delivery by therapists with low caseloads. Thus, given the multiple needs of suicidal youths, MST was examined as a viable alternative to acute hospitalization with aftercare.

The present manuscript is a critical part of the research emanating from a randomized trial comparing MST with inpatient psychiatric hospitalization for youths presenting mental health emergencies. The initial and follow-up evaluations focused on broad clinical (Henggeler et al., 1999, 2003) and service level (Schoenwald et al., 2000) outcomes. In light of the nature of the sample, this study focuses on outcomes pertaining to attempted suicide and symptoms closely associated with this life-threatening problem. Based on data from youths and primary caregivers collected through 16 months after recruitment, two primary hypotheses were considered with regard to the role of MST in reducing attempted suicides in youths. First, MST was hypothesized to be more effective than hospitalization at decreasing attempted suicide and suicidal ideation, improving the youth's affective state (i.e., depressive affect, hopelessness), and improving parental functioning (i.e., parental control). Second, given that age and developmental status (Wichstrom, 2000), ethnicity (Brent et al., 1988), and gender (Hollis, 1996; Spirito et al., 1991) have been found to interact with other precipitating factors to alter the risk of suicidal ideation and behavior, these factors were assessed as potential moderators influencing the effectiveness of MST on attempted suicide.

\section{METHOD}

\section{Participants}

Participants were 156 youths who were approved for emergency psychiatric hospitalization at the Medical University of South Carolina because of suicidal ideation/planning or attempted suicide, homicidal ideation or behavior, psychosis, or other threat of harm to self or others. Youths were included if they were (1) aged 10 to 17, (2) Medicaid-funded or without health insurance, and (3) residing in a noninstitutional environment such as the home of a family member or relative, foster home, or shelter. Although youths were excluded if they received a diagnosis of autism, no additional exclusionary criteria were used based on other preexisting mental health, physical health, or intellectual difficulties.

The youths were predominantly male $(65 \%)$ and had an average age of 12.9 years $(S D=2.1)$. Sixty-five percent were African American, 33\% European American, and 1\% other. At time of entry into the study, $31 \%$ percent of the youths lived in two-parent households that included at least one biological or adoptive parent, 51\% lived in single-parent households that included at least one biological or adoptive parent, and $18 \%$ lived with someone other than a biological or adoptive parent. Youths were predominantly from low socioeconomic backgrounds, with $69 \%$ of families receiving Aid to Families with Dependent Children, food stamps, Supplemental Security Income, or some other form of government aid, and with $79 \%$ receiving Medicaid. 
Hospital referral for suicidal ideation, suicide planning, and attempted suicide at pretreatment was derived from hospital admission intake records. Records were coded for the following referral problems: (1) suicidal ideation, (2) suicide plan, (3) suicide attempt, (4) homicidal ideation, (5) homicidal plan, (6) homicide attempt, (7) psychosis, and (8) other threat of harm to self or others. Based on these records, $51 \%$ of the youths were classified as suicidal (suicide ideation, plan, or attempt) at intake and $49 \%$ were classified as nonsuicidal.

\section{Procedures}

Families were recruited for inclusion at the hospital's emergency department or inpatient admission office and then randomly assigned to either the MST or hospitalization condition (see Henggeler et al., 1999, for details on recruitment and treatment assignment). Data from three evaluation periods are included in this study: within 24 hours of acceptance into the project; at the completion of MST home-based services (an average of 4 months after recruitment); and approximately 1 year following treatment termination, with the yoked comparison case assessed at the same time. Families were paid $\$ 50$ for each completed assessment.

\section{Treatment Conditions}

Multisystemic Therapy. The MST clinical protocol is specified in a manual designed for the treatment of antisocial youths (Henggeler et al., 1998) and has been adapted for the treatment of psychiatrically distressed youths (Henggeler et al., 2002). MST is a familycentered, home-based intervention that targets the multiple systems in which the youth and family are embedded. MST adopts Bronfenbrenner's (1979) social-ecological model of human development, which suggests that problem behaviors are often maintained by problematic transactions within and across the multiple systems of the youth's social ecology. MST therapists intervene primarily at the family level, (1) empowering caregivers with the skills and resources they need to communicate with, monitor, and discipline their children effectively; (2) assisting caregivers in engaging their children in prosocial activities while disengaging the youth from deviant peers; and (3) addressing individual and systemic barriers to effective parenting. To achieve these ends, MST is delivered in the family's natural environment (e.g., home, school, community) by therapists trained in the use of a variety of evidence-based interventions (e.g., contingency contracting, communication training, behavioral parent training). MST is intensive (contact is daily when needed) yet time-limited (services range from 3 to 6 months), requiring that therapist caseloads be fairly low compared with traditional services (caseloads of 4-6 families). In addition, MST therapists are guided by a set of nine treatment principles that offer general guidelines that direct case conceptualization, treatment specification, and prioritization of interventions, and ongoing quality assurance to support treatment fidelity is intensive (Henggeler et al., 2002).

In accordance with the MST treatment principles adapted for the treatment of youths in psychiatric crisis, MST therapists adopt a handful of core strategies to minimize the risk of self-harm among suicidal youths. These strategies include (1) development of a safety plan with the family requiring that potentially lethal suicidal methods (e.g., guns, lethal medications, knives, sheets) be secured or eliminated; (2) containment and monitoring of youth by caregivers, particularly when negative influences are present in the community; (3) disengagement from deviant peers who may precipitate a suicidal episode; and (4) helping responsible adults in the natural ecology provide monitoring and structure to diminish suicide risk (Henggeler et al., 2002). Particular attention was given to targeting the methods used by the youth in previous suicidal episodes.
Hospitalization. Youths assigned to the hospitalization condition were admitted to the Youth Division Inpatient Psychiatric Unit at the Medical University of South Carolina. The primary goals were to provide acute stabilization and psychiatric evaluation and establish an aftercare plan, typically with the local community mental health center. Youths were served by a multidisciplinary team including a child psychiatrist, child psychiatry resident, general psychiatry resident, social worker, special education teacher, and nursing staff. The unit has a behaviorally based milieu program with a point system that is individualized to each youth, targeting the behaviors that precipitated admission. For youths with a moderate to high risk of suicidal behavior, hospital staff were instructed to implement additional procedures that maximized the youth's safety while on the unit (e.g., checks by nursing staff every 15 minutes, mouth checks following administration of oral medications, prohibition of potentially lethal items such as belts and shoelaces). After discharge, the team attempted to match the youth's needs with available mental health providers in the community.

It is important to note that $44 \%$ of MST youths were also admitted for psychiatric hospitalization during the course of treatment due to emergencies that could not be handled in community settings. To maintain treatment integrity, when an MST youth required hospitalization, care was taken to separate the youth from the regular inpatient population (Henggeler et al., 1999). Regardless, the MST condition included both those who did and did not receive psychiatric hospitalization during the treatment period.

\section{Measures}

Parental Control. Parental control was evaluated using youth and caregiver reports on the Family, Friends, and Self Scale (FFS) (Simpson and McBride, 1992), a 60-item questionnaire designed to assess a youth's social relationships and psychological adjustment. Items are rated on a scale from 0 ("never") to 4 ("almost always"). For this study the control subscale was used as an index of parental control (e.g., "Do your parents let you go anywhere you please without asking?"). Alpha coefficients for caregiver $(\alpha=.63)$ and youth $(\alpha=.63)$ reports on the control subscale were only modest for this sample; however, previous research suggests that the youth version of this scale has good reliability and predictive validity (Simpson and McBride, 1992).

Depressive Affect. Measures of youth depressive affect were derived from three sources. First, youths completed the depression subscale of the Brief Symptom Inventory (BSI) (Derogatis, 1992), which included six items indicating dysphoric mood and affect over the past 7 days. Items were rated on a scale from 0 ("not at all") to 4 ("extremely"). Because one item on this scale was indicative of suicidal thinking, and we were also creating an index of depression independent of suicidality, a strategy used by other investigators was followed (e.g., Brent et al., 1986), and this item was deleted from the depression scale. Thus, the final scale included five items (e.g., "How often have you experienced feelings of worthlessness") with $\alpha=.85$.

The anxiety/depression subscale of the Child Behavior Checklist (CBCL) (Achenbach, 1991) served as a second index of depressive affect. The CBCL requires caregivers to rate 118 child behavior problems on a scale from 0 ("not true") to 2 ("very often true") over the past 6 months. Sample items include "unhappy, sad, depressed" and "underactive." The 14 items that formed the anxiety/depression scale showed good internal consistency $(\alpha=.87)$.

Hopelessness, defined as negative expectations toward the future, constituted a final index of depression. According to cognitive models of depression, hopelessness represents a core cognitive feature of depression in adults and children (Kashani et al., 1992). Hopelessness was measured by youth self-report on the 17-item Hopeless- 
ness Scale for Children (Kazdin et al., 1986), with each item rated as true or false for the past 2 weeks. Sample items included "All I can see ahead of me are bad things, not good things" and "I will have more good times than bad times." The internal consistency of this scale was acceptable $(\alpha=.79)$.

Suicidal Ideation. The presence of suicidal ideation was evaluated using items from youth self-report on both the BSI (see above) and the Youth Risk Behavior Survey (YRBS) (Kolbe et al., 1993). From the BSI, two items ("How often did you have thoughts of ending your life" and "How often did you have thoughts of death or dying") were used to construct the first index of suicidal ideation. Suicidal ideators were considered those who gave a positive rating for either of these items (i.e., provided a rating between " 1 " and "4").

From the YRBS, the item "Did you seriously consider attempting suicide during the past 12 months?" was used as a second index of youth suicidal ideation. The YRBS is a 53-item survey developed by the Centers for Disease Control and Prevention (CDC) to evaluate risk behaviors among school-based youngsters across the United States. The YRBS was used in 1991 with a national sample of 12,272 youths to establish national prevalence rates for health risk behaviors among students in grades 9 through 12 (Brener et al., 1995). Evidence suggests good test-retest reliability on this item among middle- and high-school students ( $\kappa=0.76$; Brener et al., 1995).

Attempted Suicide. Two independent sources were used to evaluate attempted suicide. First, a single item representing the frequency of self-harm behavior from the caregiver's perspective ("Deliberately harms self or attempts suicide?") was selected from the CBCL. Responses ranged from 0 ("not true") to 2 ("very true or often true"). A second index of attempted suicide was a single item taken from youth self-report on the YRBS that represented the number of times the youth attempted suicide in the past 12 months (i.e., "How many times did you actually attempt suicide?"). Responses ranged from 0 ("0 times") to 4 ("6 or more times"). Because of the extremely skewed response distribution (i.e., the vast majority of respondents in both treatment conditions reported no suicide attempt at posttreatment and follow-up), the two attempted suicide variables were dichotomized into "yes" (indicating that suicidal behavior occurred) or "no" (indicating that suicidal behavior did not occur).

\section{Data Analysis}

Mixed-effects growth modeling was used to examine the effects of treatment on indices of depressive affect and parental control (Bryk and Raudenbush, 1992). However, because the attempted suicide and suicidal ideation dependent variables were essentially binomial (i.e., youths were either suicidal or not suicidal), standard mixed-model assumptions (e.g., normality and homogeneity of variance) were violated. Thus, for the suicidality indices, generalized linear mixed-model analysis (GLM) was used (Littell et al., 1996). GLMs are extensions of fixed linear models to cases where standard linear-model assumptions are violated.

For each analysis, we evaluated whether the two treatment conditions differed in terms of their linear (i.e., no change of direction versus continuous symptom decline) or quadratic (curvilinear with a single change in direction versus symptom decline followed by maintenance of treatment gains) effects. Subsequently, we evaluated whether the youth's age, gender, and ethnicity moderated these effects.

\section{RESULTS}

\section{Outcomes}

Table 1 presents the percentage of youths who were suicide attempters or ideators before treatment, after treatment, and at the 1-year follow-up for both the MST and hospital conditions. Also included are means and standard deviations for continuous variables, as well as significance tests for time and treatment effects. Significant linear time effects were found for caregiverand youth-rated attempted suicide, youth-rated suicidal ideation, caregiver-rated anxious/depressed, youth-rated depressive affect, and youth-rated hopelessness, suggesting that MST and hospitalization were both associated with decreased symptomatology over time.

Significant linear and quadratic treatment effects were found for youth-rated attempted suicide. These results indicate that MST was significantly more effective than psychiatric hospitalization at reducing attempted suicide over the course of 16 months following recruitment. Furthermore, the groups differed in their symptom trajectory. Before treatment, MST youths reported a higher frequency of attempted suicide, but over the course of treatment and follow-up the frequency declined sharply relative to hospitalized youths. No significant treatment effects were found for caregiver-rated attempted suicide.

However, significant quadratic treatment effects were found for caregiver-rated parental control. Whereas caregivers of hospitalized youths reported constant levels of parental control over time, caregivers of MST youths reported an increase in parental control from before to after treatment, but the levels returned to baseline by the 1-year follow-up. MST appeared to have no long-term, differential effects on suicidal ideation, youth depressive affect, or youth-rated parental control.

\section{Moderator Effects}

Further tests were conducted to determine whether certain characteristics of the youth (i.e., age, gender, ethnicity) influenced the direction or strength of treatment effects. Thus, condition $\times$ time $\times$ moderator analyses were conducted to evaluate whether these variables moderated the effects of treatment on subsequent suicide attempts.

With respect to linear effects, no significant moderator effects were found for caregiver-rated attempted suicide. However, regarding quadratic effects, results indicated that age $\left(t_{290}=3.47, p<.05\right.$; Fig. 1 , $\mathrm{a}$ and $\left.\mathrm{b}\right)$, gender $\left(t_{290}=6.49, p<.01\right.$; Fig. $1, \mathrm{c}$ and $\left.\mathrm{d}\right)$, and ethnicity $\left(t_{286}=4.81, p<.01\right.$; Fig. 1 , e and $\left.\mathrm{f}\right)$ each moderated the effects of MST on caregiver-rated attempted suicide. An analysis of quadratic effects within 
TABLE 1

Group Proportions or Means (and Standard Deviations) for Suicidality, Depressive Affect, and Parental Control

\begin{tabular}{|c|c|c|c|c|c|c|}
\hline & Pretreatment & Posttreatment & 1-yr Follow-up & $\begin{array}{c}\text { Time Effect: } \\
t \text { (Linear) }\end{array}$ & $\begin{array}{c}\text { Treatment Effect: } \\
t \text { (Linear) }\end{array}$ & $\begin{array}{l}\text { Treatment Effect: } \\
t \text { (Quadratic) }\end{array}$ \\
\hline & $\%$ & $\%$ & $\%$ & & & \\
\hline \multicolumn{7}{|c|}{ YRBS Attempted Suicide } \\
\hline MST & 31 & 14 & 4 & $-6.01^{* * *}$ & $2.61^{* *}$ & $3.60^{* * *}$ \\
\hline Hospital & 19 & 9 & 4 & & & \\
\hline \multicolumn{7}{|c|}{ CBCL Attempted Suicide } \\
\hline MST & 46 & 22 & 9 & $-5.25^{* * *}$ & 1.57 & -0.31 \\
\hline Hospital & 40 & 30 & 17 & & & \\
\hline \multicolumn{7}{|c|}{ BSI Suicidal Ideation } \\
\hline MST & 60 & 35 & 19 & $-5.97^{* * *}$ & 1.55 & -0.40 \\
\hline Hospital & 55 & 40 & 29 & & & \\
\hline \multicolumn{7}{|c|}{ YRBS Suicidal Ideation } \\
\hline MST & 37 & 25 & 15 & $-3.37^{* *}$ & -0.29 & 0.85 \\
\hline \multirow[t]{2}{*}{ Hospital } & 42 & 21 & 16 & & & \\
\hline & Mean (SD) & Mean (SD) & Mean (SD) & & & \\
\hline \multicolumn{7}{|c|}{ CBCL Anxious/Depressed } \\
\hline MST & $66.76(12.39)$ & $60.43(11.82)$ & $57.73(9.76)$ & $-5.70^{* * *}$ & -0.49 & 0.47 \\
\hline Hospital & $66.81(11.10)$ & $59.14 \quad(9.69)$ & $56.81(8.68)$ & & & \\
\hline \multicolumn{7}{|c|}{ BSI Depression } \\
\hline MST & $1.07 \quad(1.10)$ & $0.68 \quad(0.93)$ & $0.60(0.84)$ & $-3.47^{* * *}$ & -0.23 & -0.31 \\
\hline Hospital & $1.21 \quad(1.15)$ & $0.83 \quad(0.97)$ & $0.70(0.87)$ & & & \\
\hline \multicolumn{7}{|l|}{ Hopelessness } \\
\hline MST & $5.32 \quad(3.55)$ & $4.53(3.33)$ & $3.84(3.39)$ & $-2.65^{* *}$ & -0.82 & 0.94 \\
\hline Hospital & $6.09 \quad(4.14)$ & $4.47 \quad(3.23)$ & $3.93(2.99)$ & & & \\
\hline \multicolumn{7}{|c|}{ FFS Control Scale, Caregiver } \\
\hline MST & $2.85(0.58)$ & $3.06 \quad(0.54)$ & $2.87(0.59)$ & 0.33 & -0.43 & $2.08^{*}$ \\
\hline Hospital & $2.92 \quad(0.62)$ & $2.95 \quad(0.51)$ & $2.92(0.54)$ & & & \\
\hline \multicolumn{7}{|c|}{ FFS Control Scale, Youth } \\
\hline MST & $2.48 \quad(0.73)$ & $2.53 \quad(0.75)$ & $2.39(0.80)$ & -1.13 & -1.14 & 0.85 \\
\hline Hospital & $2.58 \quad(0.75)$ & $2.46 \quad(0.73)$ & $2.33(0.79)$ & & & \\
\hline
\end{tabular}

Note: $\mathrm{BSI}=$ Brief Symptom Inventory; CBCL = Child Behavior Checklist; FFS = Family, Friends, and Self Scale; MST = multisystemic therapy; YRBS = Youth Risk Behavior Survey.

${ }^{*} p<.05 ;{ }^{* *} p<.01 ;{ }^{* * *} p<.001$.

each age, gender, and ethnic group revealed differential trends by treatment condition. As evidenced in Figure 1 , regardless of demographic category, youths in the MST condition tended to exhibit a substantial decline in suicidal behavior from before treatment to after treatment; it leveled off at the 1-year follow-up. However, the trajectory for youths in the hospital condition tended to vary considerably as a function of age, gender, and ethnicity. For example, attempted suicide in hospitalized preadolescents actually increased slightly from before to after treatment but dropped substantially in the year following treatment; conversely, attempted suicide in hospitalized adolescents dropped substantially from before to after treatment and stayed fairly constant in the year following treatment. Because all youths in some demographic categories reported no attempted suicide during certain assessment periods (e.g., at the 1-year follow-up, no females in either treatment condition self-reported any episode of attempted suicide), moderator analyses based on youth self-report of attempted suicide could not be carried out.

\section{DISCUSSION}

This report presents the first examination of MST for suicidal behavior in children and adolescents. Importantly, the results support the efficacy of MST relative to inpatient psychiatric hospitalization in reducing the frequency of attempted suicide. In addition, analysis of quadratic effects suggests that MST may contrib- 
a. Pre-Adolescents (Ages 9 - 12) (CBCL)
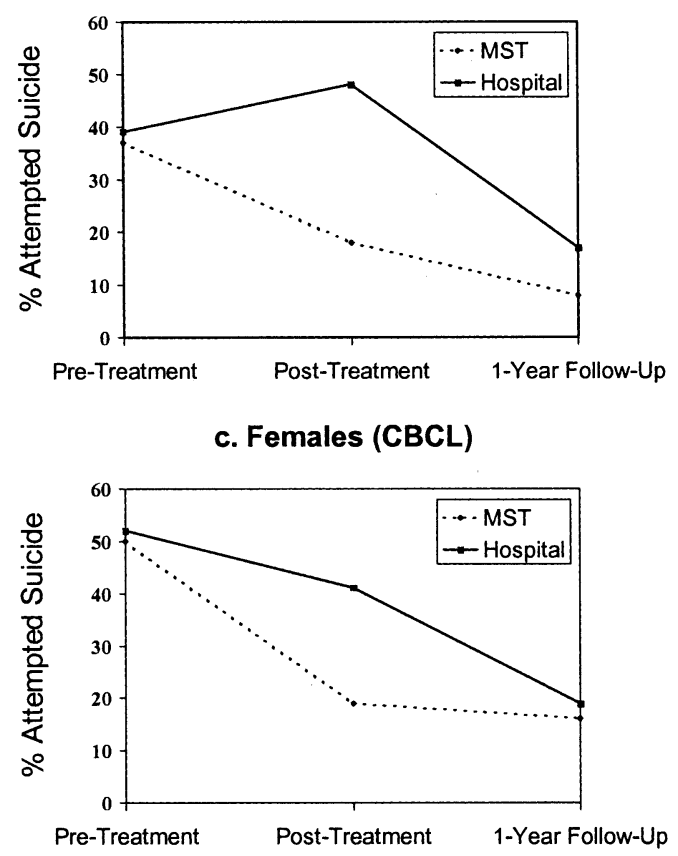

e. African-Americans (CBCL)

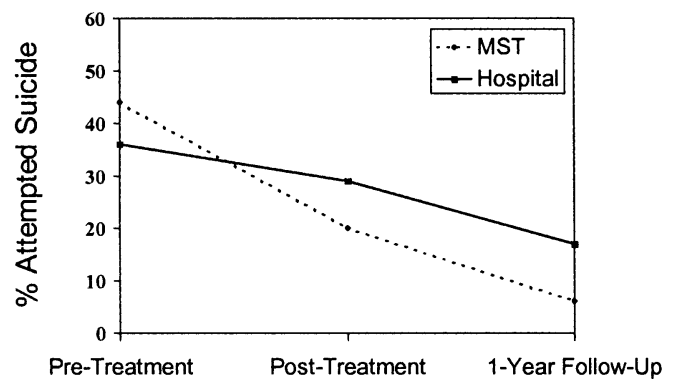

b. Adolescents (Ages 13-17) (CBCL)
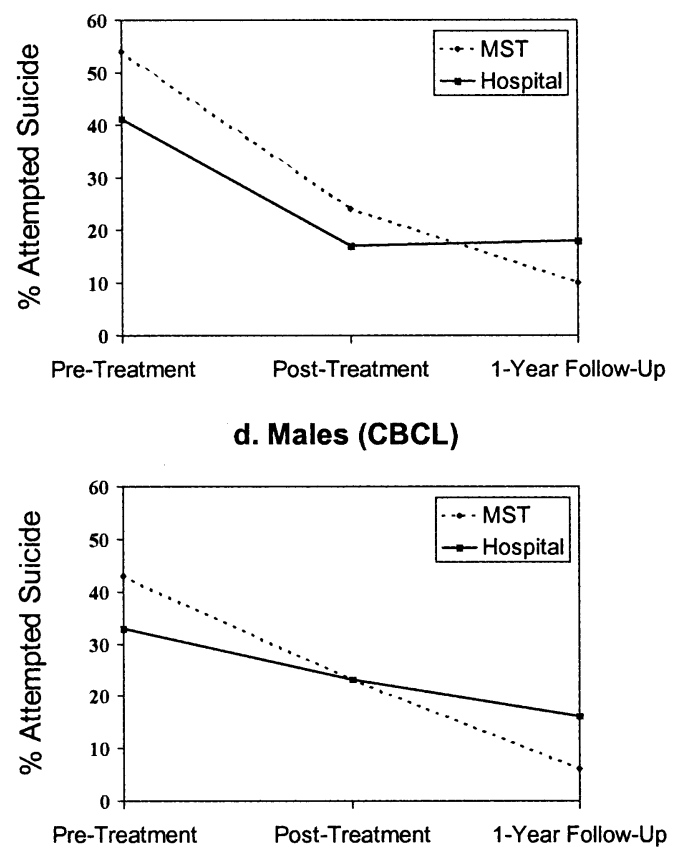

f. Euro-Americans (CBCL)

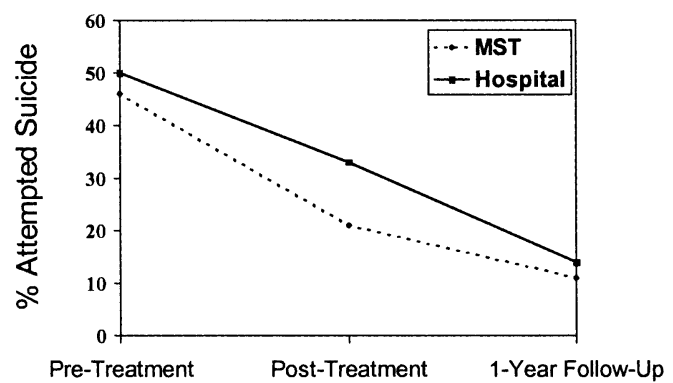

Fig. 1 Effects of multisystemic therapy (MST) versus hospitalization on caregiver-rated attempted suicide (CBCL) by age (a, b), gender (c, d), and ethnicity (e, f).

ute to more rapid symptom relief compared to hospitalization. Although several clinical trials with suicidal youths have been conducted (Harrington et al., 1998; Rotheram-Borus et al., 1996, 2001), to our knowledge this represents the first to demonstrate such significant treatment effects on self-harm behavior in youths.

An examination of the outcome slopes indicated that European Americans and African Americans followed somewhat different outcome trajectories based on treatment condition (Fig. 1). Although the trajectory for MST was nearly identical across ethnic groups, the slope for European Americans appeared steeper than that for African Americans in the hospitalization condition. This finding might suggest that African American youths who receive standard psychiatric hospitalization improve at a slower rate than their European American counterparts. However, given that African Americans in the hospital condition began treatment with a lower overall frequency of attempted suicide (based on caregiver report), an alternative interpretation is that these findings simply reflect a regression to the mean effect (see below). Regardless, given this unusual pattern, these results clearly need to be explored in greater depth.

Although MST appeared efficacious in reducing youth-rated suicidal behavior, it was not shown to be differentially effective in ameliorating three of the most robust predictors of attempted suicide in the extant literature: depressive affect, hopelessness, and suicidal ideation. Interestingly, this finding is consistent with two complementary findings from previous research. 
On the one hand, psychosocial interventions that are successful in treating depression and hopelessness among suicidal individuals have shown minimal efficacy in reducing rates of attempted suicide (Lerner and Clum, 1990; Rotheram-Borus et al., 1996, 2001). On the other hand, interventions that reduce the frequency and severity of attempted suicide in adult samples generally are not effective in ameliorating depressive affect (Linehan et al., 1991; Verkes et al., 1998). Together, these findings suggest that the change mechanisms required for the reduction of suicidal behavior might differ from those of treating depression, and that one cannot assume that suicidal risk decreases in tandem with depressive affect.

\section{Clinical Implications}

Youths in both treatment conditions showed substantial improvements in symptom presentation, yet MST was more effective than hospitalization at reducing the frequency of attempted suicide and appeared to do so in a more rapid fashion. Although very brief, family-based interventions have not proven successful in ameliorating attempted suicide, the present results suggest that a more intensive, family-based approach such as MST that addresses the multiple risk factors associated with attempted suicide should be pursued further.

MST was originally designed for the treatment of antisocial behavior but has since been applied to the treatment of child maltreatment, sexual offending, and substance abuse (Henggeler et al., 1998, 2002), and large-scale randomized effectiveness trials with these populations are in progress. This study represents the first attempt to extend MST to the treatment of suicidal youths and their families and clearly needs to be replicated and extended with an independent sample. Thus, more efforts are needed to help suicidal youths with their multiple needs and further reduce the risk for future suicidal behavior. One such effort with favorable clinical outcomes has recently been completed in Hawaii (Rowland et al., submitted), and another is underway in Philadelphia.

\section{Limitations}

Given the potential significance of these findings, several limitations should be noted. First, youths who attempt suicide are actually a heterogeneous group who often differ in terms of suicidal intent, method, lethality, and exposure to precipitating stressors (Boergers et al., 1998; Brent, 1997). Because of data limitations, we were unable to evaluate these characteristics of attempted suicide and thus risk homogenizing a diverse group of youths.

In addition, the temporal variation and overlap between several measures used in this study suggest that results should be interpreted with caution. For example, caregivers who completed the CBCL were informed to base their reports on the past 6 months, whereas youths who completed the YRBS were informed to report on behaviors occurring over the past 12 months. Thus, it is possible that caregivers and youths were basing their ratings of attempted suicide on different time perspectives. The assessment of parental control presented an additional measurement concern. The internal reliability of the parental control scale for both caregiver and youth report fell below the accepted norm of 0.70 ; thus, results based on this scale should be interpreted with this limitation in mind.

Also, in view of the fact that MST youths had significantly higher rates of attempted suicide before treatment, it is possible that the superior effects of MST reflect a regression to the mean effect. Since the median suicide reattempt rate for youths is only about $5 \%$ to $15 \%$ per year (Brent, 1997), and since rates of attempted suicide dropped substantially in both treatment conditions, the dramatic decrease in symptomatology among MST youths over the 1-year assessment period may reflect the natural course of attempted suicide in children. We are currently evaluating the youths at 2.5 years after the intervention to determine whether these presumed treatment effects are lasting.

Finally, several characteristics of the sample may limit generalization to other populations. Even though minimal exclusion criteria were used, the sample was composed of predominantly African American and low-income families who presented at a hospital for psychiatric emergencies. Although the rate of suicide has increased among African Americans in recent decades, African American youths are still underrepresented among suicide attempters (Grunbaum et al., 2002). Furthermore, since previous research suggests that suicide attempters who receive mental health treatment differ in important ways from those who do not (Taylor and Stansfeld, 1984), these results may not be generalizable to community samples of suicidal youths.

Disclosure: Drs. Henggeler and Rowland are stockholders in MST Services Inc., which has the exclusive licensing agreement through the Medical University of South Carolina for the dissemination of MST technology and intellectual property. 


\section{REFERENCES}

Achenbach TM (1991), Manual for the Child Behavior Checklist/4-18 and 1991 Profile. Burlington: University of Vermont, Department of Psychiatry

Boergers J, Spirito A, Donaldson D (1998), Reasons for adolescent suicide attempts: associations with psychological functioning. J Am Acad Child Adolesc Psychiatry 37:1287-1293

Brener ND, Collins JL, Kann L, Warren CW, Williams BI (1995), Reliability of the Youth Risk Behavior Survey Questionnaire. Am J Epidemiol 141:575-580

Brent DA (1997), Practitioner review: the aftercare of adolescents with deliberate self-harm. J Child Psychol Psychiatry 38:277-286

Brent DA, Kolko DJ, Wartella ME et al. (1993a), Adolescent psychiatric inpatients' risk of suicide attempt at 6-month follow-up. J Am Acad Child Adolesc Psychiatry 32:95-105

Brent DA, Perper JA, Goldstein CE et al. (1988), Risk factors for adolescent suicide: a comparison of adolescent suicide victims with suicidal inpatients. Arch Gen Psychiatry 45:581-588

Brent DA, Perper JA, Moritz G et al. (1993b), Psychiatric risk for adolescent suicide: a case control study. J Am Acad Child Adolesc Psychiatry 32:521-529

Brent DA, Robert K, Edelbrock C, Costello AJ, Dulcan MK, Conover N (1986), Psychopathology and its relationship to suicidal ideation in childhood and adolescence. J Am Acad Child Psychiatry 25:666-673

Bronfenbrenner U (1979), The Ecology of Human Development: Experiments by Nature and Design. Cambridge, MA: Harvard University Press

Bryk AS, Raudenbush SW (1992), Hierarchical Linear Models: Applications and Data Analysis Methods. Newbury Park, CA: Sage

Centers for Disease Control and Prevention (2002), Emergency medical system responses to suicide-related calls: Maine, November 1999-October 2000. MMWR 51:56-59

Derogatis LR (1992), The Brief Symptom Inventory: Administration, Scoring, and Procedures Manual. Baltimore: Clinical Psychometric Research, Johns Hopkins

Grunbaum JA, Kann L, Kinchen SA et al. (2002), Youth risk behavior surveillance: United States, 2001. MMWR 51:1-62

Harrington R, Kerfoot M, Dyer E et al. (1998), Randomized trial of a home-based family intervention for children who have deliberately poisoned themselves. J Am Acad Child Adolesc Psychiatry 37:512-518

Henggeler SW, Rowland MD, Halliday-Boykins C et al. (2003), One-year follow-up of multisystemic therapy as an alternative to the hospitalization of youths in psychiatric crisis. J Am Acad Child Adolesc Psychiatry 42:543-551

Henggeler SW, Rowland MD, Randall J et al. (1999), Home-based multisystemic therapy as an alternative to the hospitalization of youths in psychiatric crisis: clinical outcomes. J Am Acad Child Adolesc Psychiatry 38:1331-1339

Henggeler SW, Schoenwald SK, Borduin CM, Rowland MD, Cunningham PB (1998), Multisystemic Treatment of Antisocial Behavior in Children and Adolescents, Barlow DH, ed. New York: Guilford

Henggeler SW, Schoenwald SK, Rowland MD, Cunningham PB (2002), Multisystemic Treatment of Children and Adolescents With Serious Emotional Disturbance. New York: Guilford

Hollis C (1996), Depression, family environment, and adolescent suicidal behavior. J Am Acad Child Adolesc Psychiatry 35:622-630

Kashani JH, Dandoy AC, Reid JC (1992), Hopelessness in children and adolescents: an overview. Acta Paedopsychiatr 55:33-39

Kazdin AE, Rodgers A, Colbus D (1986), The Hopelessness Scale for Children: psychometric characteristics and concurrent validity. J Consult Clin Psychol 54:241-245
Kazdin AE, Weisz JR (1998), Identifying and developing empirically supported child an adolescent treatments. J Consult Clin Psychol 66:19-36

King CA (1997), Suicidal behavior in adolescence. In: Review of Suicidology, 1997, Maris RW, Silverman MM, Canetto SS, eds. New York: Guilford, pp 61-95

Kolbe LJ, Kann L, Collins JL (1993), Overview of the youth risk behavior surveillance system. Public Health Rep 108:2-10

Lerner MS, Clum GA (1990), Treatment of suicide ideators: a problemsolving approach. Behav Ther 21:403-411

Lewinsohn PM, Rohde P, Seeley JR (1996), Adolescent suicidal ideation and attempts: prevalence, risk factors, and clinical implications. Clin Psychol Sci Pract 3:25-46

Linehan MM, Armstrong HE, Suarez A et al. (1991), Cognitive-behavioral treatment of chronically parasuicidal borderline patients. Arch Gen Psychiatry 48:1060-1064

Littell RC, Milliken GA, Stroup WW, Wolfinger RD (1996), SAS System for Mixed Models. Cary, NC: SAS Institute

Piacentini J, Rotheram-Borus MJ, Cantewell C (1995), Brief cognitivebehavioral family therapy for suicidal adolescents. In: Innovations in Clinical Practice: A Source Book, Vol 14, VandeCreek L, Knapp S, Jackson T, eds. Sarasota, FL: Professional Resources Press, pp 151168

Rotheram-Borus MJ, Piacentini J, Cantwell C, Belin TR, Song J (2001), The 18-month impact of an emergency room intervention for adolescent female suicide attempters. J Consult Clin Psychol 68:1081-1093

Rotheram-Borus MJ, Piacentini J, Van Rossem R et al. (1996), Enhancing treatment adherence with a specialized emergency room program for adolescent suicide attempters. I Am Acad Child Adolesc Psychiatry 35:654-663

Schoenwald SK, Ward DM, Henggeler SW, Rowland MD (2000), MST vs. hospitalization for crisis stabilization of youth: placement outcomes 4 months post-referral. Ment Health Serv Res 2:3-12

Shaffer D, Piacentini J (1994), Suicide and attempted suicide. In: Child and Adolescent Psychiatry, 3rd ed, Rutter M, Hersov L, Taylor E, eds. London: Blackwell Scientific Publications, pp 407-424

Simpson DD, McBride AA (1992), Family, Friends, and Self (FFS) assessment scales for Mexican American youth. Hisp J Behav Sci 14:327340

Spirito A, Overholser J, Hart K (1991), Cognitive characteristics of adolescent suicide attempters. I Am Acad Child Adolesc Psychiatry 30:604608

Spirito A, Plummer B, Gispert M et al. (1992), Adolescent suicide attempts: outcomes at follow-up. Am J Orthopsychiatry 62:464-468

Swedo SE (1989), Postdischarge therapy of hospitalized adolescent suicide attempters. J Adolesc Health Care 10:541-544

Taylor EA, Stansfeld SA (1984), Children who poison themselves, II: prediction of attendance for treatment. Br J Psychiatry 145:127-135

US Public Health Service (2001), Youth Violence: A Report of the Surgeon General. Washington, DC: US Public Health Service (available at www.surgeongeneral.gov/library/youthviolence)

Verkes RJ, Van der Mast RC, Hengeveld MW, Tuyl JP, Zwinderman AH, Van Kempen MJ (1998), Reduction by paroxetine of suicidal behaviors in patients with repeated suicide attempts but not major depression. Am J Psychiatry 155:543-577

Wagner BM (1997), Family risk factors for child and adolescent suicidal behavior. Psychol Bull 121:246-298

Wichstrom L (2000), Predictors of adolescent suicide attempts: a nationally representative longitudinal study of Norwegian adolescents. J Am Acad Child Adolesc Psychiatry 39:603-610 